\title{
Substance misuse from adolescence to adulthood: service issues
}

\author{
HaRITH SwadI, Senior Registrar, Guy's Hospital, London SE1 and Medway Health \\ Authority, Kent; and HARRY ZeITLIN, Senior Lecturer, Westminster Children's \\ Hospital, London SW1
}

Professionals dealing with young drug misusers, those providing mental health services for children, and those providing services for adult misusers have roles that converge and overlap (though occasionally diverge). While services for adult misusers may have been developing at a reasonable (though not to everyone's satisfaction) pace, those for adolescent misusers have not. The current substance misuse services can be described as deficient in three main areas:

First, children of addicts obtain the care they need only rarely, and mostly in cases where blatantly demonstrable harm has already occurred, e.g. physical and/or sexual abuse. No preventive services exist, despite the well documented social, developmental, psychological, psychosocial, and physical risks they face (see Sowder \& Burt, 1980).

Second, there are no special provisions for adolescent misusers, and whatever is available is fragmentary. Only one of London's Drug Dependency Units expressed a special interest in adolescent substance misuse (Swadi, unpublished data), and no more than three residential units for adolescents exist nationwide. Thus, some adolescent misusers are referred to child and adolescent psychiatry (CAP) services, others to adult substance misuse (ASM) services and perhaps the majority to 'counselling agencies'. By their very nature, none of these agencies has been in a position that enables them to provide an adequate and comprehensive service. The patterns of substance misuse, the therapeutic needs, and the approaches to meet these needs differ in adolescents from adults (Friedman \& Glickman, 1986).

Third, no formal, well defined links between ASM services and CAP services exist. Even if the badly needed, specialised services for adolescent drug users existed, the need for special collaboration between services will still continue, bearing in mind issues such as continuity of care, preventive work, the transition from adolescence to adulthood, and changes in the patterns of substance misuse. At present only isolated initiatives for coordination exist, depending on individual interests.

The following is an attempt to outline a framework for service organisation and liaison between CAP Services and ASM services. Within this context, there are five closely interlinked and overlapping areas of potential cooperation, liaison and joint work: treatment, prevention, training, research and planning.

\section{Treatment}

A member of each relevant service should be designated as having a 'special interest' in the problems of young drug misusers. Each identified professional should aim to improve his/her knowledge of the other service in order to develop a unified approach to clinical management and resource availability. They should have available to them all the resources needed as well as access to other services if required. The names of the key workers should be available to GPs, paediatricians, mental health professionals, education authorities, the law system, and organisations working with young and older drug misusers. They should be available for quick consultation and possible referrals.

Family therapy is now recognised as a helpful measure in dealing with substance misuse (see Stanton \& Todd, 1982). Within the NHS, family therapy is largely available through CAP services. The use of CAP expertise in this field by ASM services is just one possibility among many worth exploring.

There is also a need for both services to develop and define a framework for meeting the therapeutic needs of families, especially in cases where the care of children is legally contested.

\section{Prevention}

There needs to be recognition that investment in adolescent services could reduce the subsequent burden on ASM services. Prevention should have a priority equal to treatment. The two services can genuinely help each other; successful treatment of adult misusers may help prevent damage to children, and preventing substance misuse or its progression in adolescents may reduce the incidence of substance dependence among adults. It may be useful to involve other agencies such as education, social 
services, probation services and the police in prevention efforts.

Prevention may also extend to involve children of 'addicts'. Thus, joint review meetings between the two services, involving multidisciplinary teams, should be regularly carried out. Their aims would be to focus on children of substance misusers (including alcohol), as well as adolescent drug misusers. This is to ensure the care and protection of children of addicts, the smooth transition of care for grown-up adolescent users, and the planning of family support and intervention for both adult and adolescent misusers.

\section{Training}

Joint training and awareness programmes for staff at both units and outside staff, especially those who work within child health, should be arranged, for example, family therapy training for ASM staff. Both departments can take initiatives in organising training activities for other concerned agencies, e.g. probation services, social services, health visitors, community nurses ... etc. to increase awareness and help detect and identify those at risk, as well as to facilitate the services those agencies provide.

Higher psychiatric training may aid this process by involving psychiatric trainees in CAP or in substance misuse for a reasonable period of training in relevant aspects of ASM or CAP respectively.

\section{Research}

Joint research into the epidemiological aspects of adolescent substance misuse will enable adult services to predict trends and therefore allow for better planning and more efficient distribution of resources. Research should extend into preventive aspects, predicting early indicators and risk factors for substance misuse, and understanding the impact of psychologically disturbed children on substance misusing parents. An excellent area of joint research would be to develop a longitudinal design; for example, follow-up studies of adolescent users into adulthood, and studies of the financial implications of adolescent 'prevention' and 'intervention' for adult services.

\section{Planning}

The seeds of substance misuse and subsequent dependence are mostly sown in the teens (Friend \& Koushki, 1984), but can extend to cover adolescence, early adulthood and late adulthood. Thus, it makes sense to aim for active participation of CAP services in the planning of substance misuse services for adults and adolescents. Furthermore, only with the cooperation of adult services can CAP services plan their service strategies for children and families 'at risk'.

All the above, in the current cost-oriented era, have financial and budgetry implications. However, if that spending on one service is likely to be profitable for the other, it is recognised these issues may become of minor relevance.

\section{References}

Friedman, A. \& Glickman, N. (1986) Program characteristics from successful treatment of adolescent drug abuse. Journal of Nervous and Mental Disease, 174, 669-679.

FrIEND, K. \& KoushixI, P. (1984) Student substance use: stability and changes across college years. The International Journal of the Addictions, 19, 571-575.

SOWDER, B. \& BURT, M. (1980) Children of Heroin Addicts. New York: Praeger.

Stanton, M. \& TODD, T. (1982) The Family Therapy of Drug Abuse and Addiction. New York: Guilford Press. 